\section{Sensitivity relief for kids}

Dr Ranj Singh, from CBeebies' 'Get Well Soon' programme, is guest editor of the November issue of Healthy Child, which will provide a wealth of information and advice to help parents make the best decisions for their children's wellbeing and development.

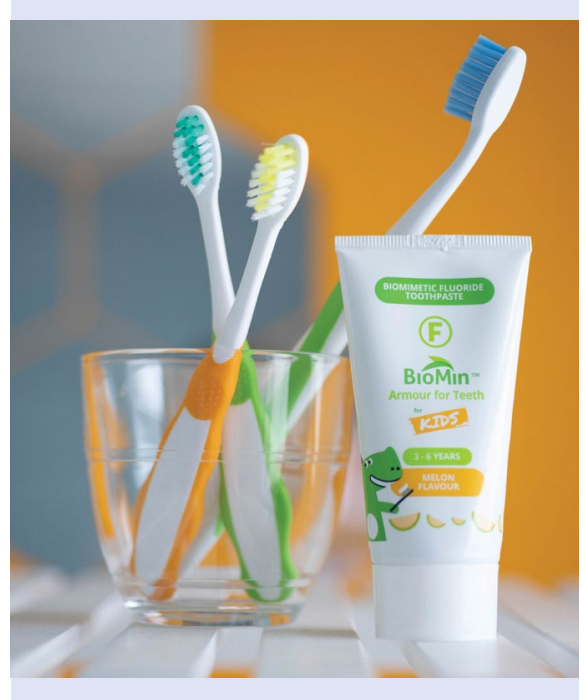

In the November issue, Dr Ranj is covering some of the common problems affecting UK children including shocking research that nearly a third of five-year-olds and nearly half of eight-year-olds have obvious tooth decay in their primary teeth. Also, that $35 \%$ of 12 -year-old children are too embarrassed to smile or laugh due to tooth decay or missing teeth.

The magazine will be freely available via WHSmith and WHSmith Travel, 30 paediatric hospitals and to 120,000 paid subscribers, a total circulation of about 500,000 UK families.

Supplied by Trycare, in strawberry and melon flavour, BioMin for Kids is available exclusively from dental practices on the high street.

BioMin F for Kids enables patients to enhance their smile and improve their oral health and comfort. It is the only toothpaste approved by the Oral Health Foundation for sensitivity relief and remineralisation.

For further information visit the Trycare website, www.trycare. co.uk/biomin, contact your local representative or call 01274885544 .

\section{Good for you and kind to the planet}

Humble is a health and wellness company offering reliable and innovative products that are good for you and kind to the planet. Humble bring lifestyle into the static and traditional oral care and wellness categories, for conscious and curious people who want appealing products without compromising quality and performance. Products are developed by dentists and designed in Sweden.

The Humble Brush (the world's most sold bamboo toothbrush) has a handle made from $100 \%$ biodegradable, sustainably grown bamboo. The bristles are made of nylon- 6 bristles from Dupont. The packaging is eco-friendly, the box and inside wrapper are made from recycled materials and can be thrown out with organic waste. This toothbrush is vegan, cruelty-free and verified BPA-free.

Humble's fluoride free Toothpaste Tablets are basically regular toothpaste, minus the water. This means that the brand can save on water - there's now no need to ship regular tap water around the globe because there's plenty of water in your tap already to make this tablet to toothpaste. To use, just bite the tablet and brush as usual.

Humble's Mint Dental Floss (50M) is a dentist-approved roll of dental floss in a cardboard pack. Humble floss is made from nylon and slides easily between your teeth without shredding or breaking. The floss is coated with a mint flavouring as

\section{Happy new oral hygiene}

For a healthier 2022, support your patients to improve their daily oral hygiene.

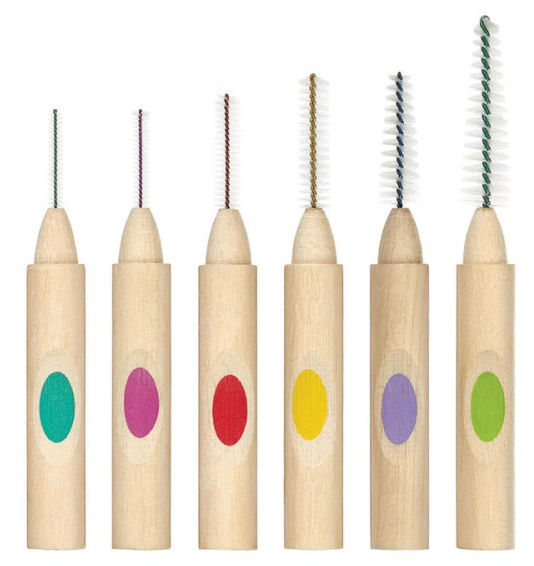

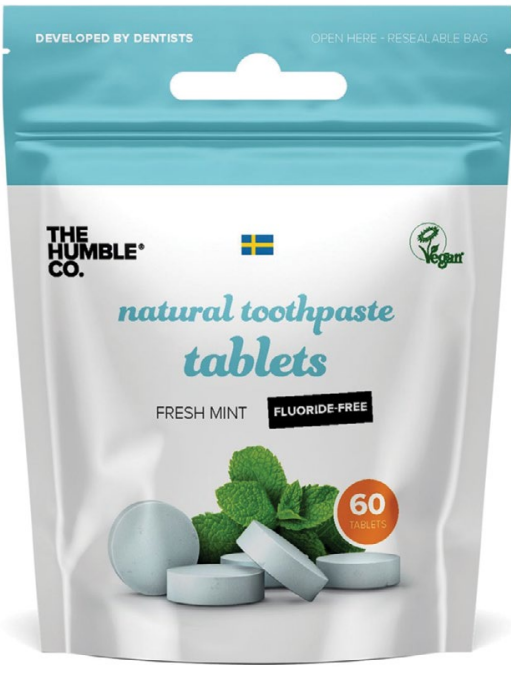

well as xylitol, to ensure that your flossing experience is as efficient, pleasant and effective as possible.

Dentist-approved Bamboo Toothpicks are made from $100 \%$ biodegradable, sustainably grown bamboo. The packaging is ecofriendly, the box and inside wrapper are made from recycled materials and can be thrown out with organic waste.

Finally, Humble's stylish Interdental Brush, with a handle from $100 \%$ sustainably grown bamboo and with quality nylon bristles from DuPont, provides an easy and practical alternative to flossing.

The BPA-free bristles on the interdental brush gently capture and remove the nasties hiding between your teeth, while the bamboo handle ensures steady handling.
For a beautifully clean mouth, the highquality products from TANDEX are all they need.

To boost toothbrushing, recommend the TANDEX WOODI interdental brush for removing optimal debris. In a range of sizes, it will fit comfortably into different spaces; using the WOODI is a pleasure! It even has a handle made from responsibly sourced birchwood, so it can be recycled.

TANDEX produces preventive tools, including brushes and interspace brushes for all ages and dental situations.

A new routine is right for a new year and so is TANDEX.

For more information on Tandex's range of products, visit https://tandex.dk/. 